\title{
Qualidade das silagens de genótipos de girassol (Helianthus annuus) confeiteiros e produtores de óleo
}

[Quality of silages of sunflower genotypes (Helianthus annuus) confectioners and oil producers]

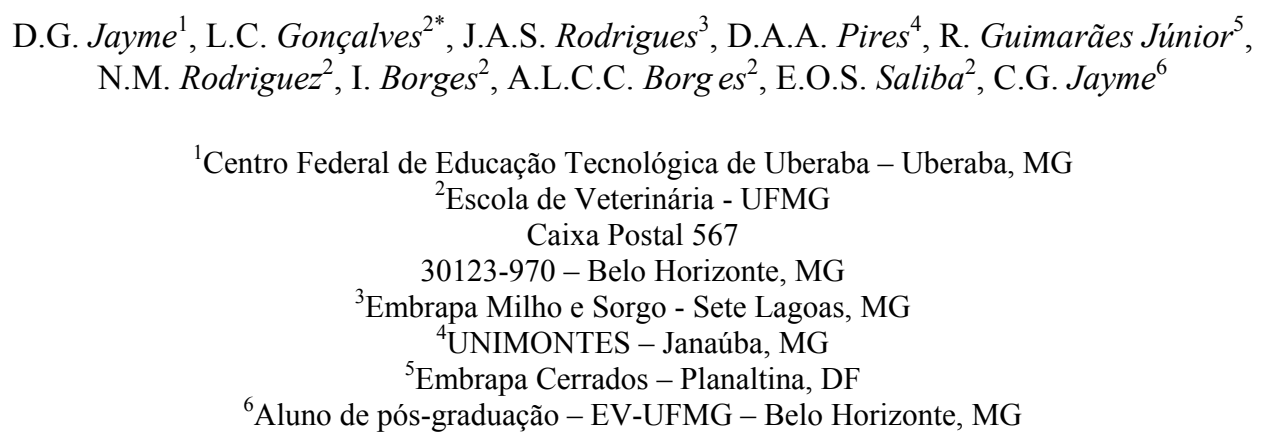

\section{RESUMO}

Avaliou-se a qualidade das silagens de três genótipos de girassol produtores de óleo (M742, IAC Uruguai e V2000) e três com sementes confeiteiras (Mycogen 93338, Victoria 807, Victoria 627). Os silos foram abertos após 56 dias de fermentação. Os menores valores de matéria seca observados foram para os genótipos Mycogen 93338 e V2000. Não foram observadas diferenças nos teores de proteína bruta entre cinco dos seis genótipos estudados. Com exceção do IAC Uruguai, os genótipos com sementes produtoras de óleo apresentaram valores de extrato etéreo mais altos que os confeiteiros. Os valores de fibra em detergente neutro variaram de $43,6 \%$ a $55,8 \%$. Os menores teores de fibra em detergente ácido foram 33,2\% para o V2000 e $35,2 \%$ para o Mycogen 93338. Não houve diferença $(\mathrm{P}>0,05)$ entre os valores obtidos para $\mathrm{N}-\mathrm{NH}_{3} / \mathrm{NT}$. O valor de $\mathrm{pH}$ médio das silagens foi de 4,51. Os maiores valores de digestibilidade in vitro da matéria seca foram 52,0\% para o V2000 e 54,5\% para o Mycogen 93338. As silagens dos genótipos confeiteiros e dos genótipos produtores de óleo foram classificadas como de boa qualidade para os parâmetros avaliados, o que demonstra o potencial do girassol como uma opção para produção de silagem na época da safrinha.

Palavras chave: girassol, qualidade da silagem, confeiteiro, produtor de óleo

\begin{abstract}
Quality of Sunflower silage was determined using genotypes Mycogen, Victoria 807, Victoria 627, M742, IAC Uruguai, V2000. The silos were opened on the 56th day of fermentation. The lowest dry matter values were for the genotypes Mycogen 93338 and V2000. In relation to the CP values, differences were not observed among five of the six genotypes. The genotypes with oil producer seed showed highest ether extract values, which were different from the confectionary variety, except IAC Uruguai. The observed values of neutral detergent fiber varied from $43.6 \%$ to $55.8 \%$. For the acid detergent fiber concentrations the genotypes V2000 with $33.2 \%$ and Mycogen with 35.2\% showed the lowest values. Differences for $\mathrm{N}-\mathrm{NH}_{3} / \mathrm{TN}$ values were not observed. The $\mathrm{pH}$ mean value of the silages was 4.51. The highest values of in vitro dry matter digestibility were obtained for the silages of the genotypes V2000 (51.2\%) and Mycogen 93338 with 54.5\%. The silages from confectionary variety as well as the silages of sunflowers oil producers were classified as good quality for the evaluated parameters, demonstrating the potential of the sunflower as an option for production of silage at the time of summer post-harvesting.
\end{abstract}

Keywords: confectionary, oil producer, quality of silage, sunflower

Recebido em 24 de maio de 2006

Aceito em 24 de agosto de 2007

*Autor para correspondência (corresponding author)

E-mail: luciocg@vet.ufmg.br 


\section{INTRODUÇÃO}

A estacionalidade da produção e da oferta de forragem como conseqüência de variáveis climáticas e do próprio manejo, vem sendo reconhecida como um dos principais limitantes à produção animal em sistemas de criação baseados em pastagens (Silva et al., 1998). Uma das práticas para melhorar a alimentação do rebanho e minimizar os efeitos da reduzida produção de forragem no período da estiagem é a conservação das forragens produzidas no verão por ensilagem (Almeida et al., 1995).

Devido às suas características de se adaptar bem em regiões onde a umidade é um fator limitante e à sua resistência ao frio (Castro et al., 1997), o girassol enquadra-se como uma boa opção onde as condições climáticas são desfavoráveis para o milho e o sorgo (MacGuffey e Shingoethe, 1980). O cultivo do girassol após a retirada da cultura de verão, com idade de corte entre $104 \mathrm{e}$ 111 dias, pode ser uma opção viável para a produção de silagem (Souza et al., 2005). Os genótipos utilizados para produção de silagem apresentam aptidão para a produção de grãos para a extração de óleo ou são materiais com sementes confeiteiras que são destinados ao consumo humano ou de aves, e ainda não existe um genótipo específico para produção de silagem. Experimentos que avaliem a qualidade das silagens de girassol obtidas com genótipos destinados à produção de óleo ou de materiais confeiteiros são importantes para que trabalhos de melhoramento genético de plantas, especificamente para produção de silagem, possam ser conduzidos.

Este trabalho teve como objetivo determinar a qualidade das silagens e seis cultivares de girassol, sendo três destinados à produção de semente confeiteira Mycogen, Victoria 807 e Victoria 627 , e três destinados à produção de óleo, V2000, M742 e IAC Uruguai.

\section{MATERIAL E MÉTODOS}

Seis cultivares de girassol foram plantados em fevereiro de 2000 nas dependências do Embrapa Milho e Sorgo localizado no município de Sete Lagoas, em Minas Gerais. O plantio foi realizado em quatro áreas distintas (blocos) com seis parcelas (uma para cada genótipo) em cada área, num total de 24 parcelas (canteiros) com quatro linhas de cinco metros de comprimento cada e 90 centímetros de espaçamento entre linhas, com densidade de plantio de 50000 plantas/ha. Como adubação de plantio foram utilizados $350 \mathrm{~kg}$ de NPK (8-28-16) e 100kg de uréia 40 dias após o plantio. Foram feitas também aplicações de boro a $2 \%$ por via foliar, na emissão dos botões florais.

Foram utilizados três genótipos confeiteiros, Mycogen 93338, Victoria 627, Victoria 807 e três produtores de óleo, V2000, M742, IAC Uruguai. O corte foi realizado nas duas fileiras centrais de cada parcela, quando $100 \%$ dos grãos apresentavam-se maduros, o material foi imediatamente picado com tamanho de partículas médio de $2 \mathrm{~cm}$ e ensilado. Foram utilizados silos de laboratório dotados de válvulas do tipo Bunsen feitos de tubos de PVC de $100 \mathrm{~mm}$ de diâmetro e $400 \mathrm{~mm}$ de comprimento. Os silos foram abertos após 56 dias de ensilagem.

Nas amostras das silagens pré-secas a $65^{\circ} \mathrm{C}$, foram feitas determinações dos conteúdos de matéria seca a $105^{\circ} \mathrm{C}$, segundo $\mathrm{AOAC}$ (Official..., 1995), de proteína bruta pelo método de Kjedhal e de extrato etéreo pelo método Soxlet, segundo AOAC(Official..., 1995), de fibra em detergente neutro, fibra em detergente ácido, hemicelulose, celulose e lignina (Van Soest, 1991), digestibilidade in vitro da matéria seca (Tilley e Terry, 1963) e no suco da silagem realizou-se a análise de $\mathrm{pH}$ e nitrogênio amoniacal em porcentagem do nitrogênio total (Official..., 1995).

As comparações das médias dos genótipos para as avaliações foram feitas utilizando-se o teste SNK ao nível de significância de 0,05 , segundo um delineamento de blocos ao acaso, utilizandose para o cálculo de análises de variância $o$ Software de Análises Estatísticas e Genéticas (Sistema..., 1997). As correlações entre as variáveis estudadas foram determinadas a 0,05 de probabilidade.

Para classificação das silagens foram utilizados os parâmetros contidos na Tab. 1 . 
Tabela 1. Parâmetros de matéria seca (MS), pH, nitrogênio amoniacal e digestibilidade in vitro da matéria seca (DIVMS) para avaliação da qualidade de silagens

\begin{tabular}{lcccc}
\hline Parâmetro & Muito boa & Boa & Média & Ruim \\
\hline${ }^{1} \mathrm{MS}(\%)$ & $30,0-35,0$ & $25,0-30,0$ & $20,0-25,0$ & $<20,0$ \\
${ }^{1} \mathrm{pH}$ & $3,6-3,8$ & $3,8-4,2$ & $4,2-4,6$ & $>4,6$ \\
${ }^{3} \mathrm{~N}_{-} \mathrm{NH}_{3}(\% \mathrm{NT})$ & $<10,0$ & $10,0-15,0$ & $15,0-20,0$ & $>20,0$ \\
${ }^{2} \mathrm{DIVMS}$ & $>63,0$ & $63,0-52,0$ & $52,0-38,0$ & $<38,0$ \\
\hline
\end{tabular}

Fonte: ${ }^{1}$ Paiva (1976); ${ }^{2}$ Paiva (1976) modificado por Nogueira (1995), ${ }^{3}$ Benachio (1965).

\section{RESULTADOS E DISCUSSÃO}

Os teores de matéria seca (MS), proteína bruta $(\mathrm{PB})$, extrato etéreo (EE), fibra em detergente neutro (FDN), fibra em detergente ácido (FDA), hemicelulose, celulose e lignina observados nas silagens estão na Tab. 2. Os menores valores de MS foram observados para os genótipos Mycogen 93338 e para o V2000 e os maiores para o IAC Uruguai e Victoria 807. As diferenças nos valores de MS podem, em parte, estar relacionadas à duração do ciclo dos genótipos, pois genótipos de ciclo tardio apresentam maiores teores de MS. Os teores de MS encontrados para os genótipos V2000 e Mycogen 93338 foram próximos aos 22,8\% obtidos por Valdez et al. (1988) e aos $21,7 \%$ a 23,5\% observados por Tomich (1999) com os híbridos AS243, AS603, Contiflor 3, M742 e Rumbosol 91. Menores teores de MS foram verificados por Tomich (1999) para o cultivar M737 ensilado quando a planta apresentava 90\% de grãos maduros, por Ribeiro et al. (2002) com o valor de $18,9 \%$ e Mizubuti et al. (2002) com $18,8 \%$, para plantas ensiladas no início de maturação fisiológica (grãos leitosos). Valores de MS mais altos, próximos aos dos genótipos Victoria 627, Victoria 807, M742 e IAC Uruguai, foram observados por Silva et al. (1998), 30,2\%, 33,0\% e 35,7\% para as densidades de semeadura de 30000, 50000 e 70000 plantas/ha respectivamente. As diferenças observadas nos teores de MS entre os genótipos aqui estudados, assim como as diferenças em relação aos dados de literatura podem, em parte, ser devidas as diferentes proporções de folha, haste e capítulo dos materiais avaliados, pois essas partes apresentam diferentes contribuições para o teor de MS. Tomich (1999) observou menores teores de MS nos receptáculos quando comparado com as demais partes da planta, para todos os cultivares estudados. Pereira et al. (1999), também encontraram diferenças entre as porcentagens de MS da haste e do capítulo.

Tabela 2. Teores de matéria seca (MS), proteína bruta (PB), extrato etéreo (EE), fibra em detergente neutro (FDN), fibra em detergente ácido (FDA), hemicelulose, celulose e lignina das silagens de genótipos de girassol (Helianthus annuus) confeiteiros e produtores de óleo

\begin{tabular}{lcccccccc}
\multicolumn{1}{c}{ Genótipos } & $\mathrm{MS}^{1}$ & ${ }^{*} \mathrm{~PB}^{2}$ & ${ }^{*} \mathrm{EE}^{3}$ & ${ }^{*} \mathrm{FDN}^{4}$ & ${ }^{*} \mathrm{FDA}^{5}$ & ${ }^{*}$ Hemicelulose $^{6}$ & ${ }^{*}$ Celulose $^{7}$ & ${ }^{*}$ Lignina $^{8}$ \\
\hline Mycogen 93338 & $22,60 \mathrm{c}$ & $9,56 \mathrm{a}$ & $10,63 \mathrm{~cd}$ & $44,63 \mathrm{c}$ & $35,15 \mathrm{c}$ & $9,48 \mathrm{a}$ & $27,68 \mathrm{c}$ & $7,48 \mathrm{a}$ \\
Victoria 627 & $31,10 \mathrm{~b}$ & $8,92 \mathrm{a}$ & $11,37 \mathrm{c}$ & $48,61 \mathrm{~b}$ & $38,66 \mathrm{~b}$ & $9,96 \mathrm{a}$ & $31,10 \mathrm{~b}$ & $7,56 \mathrm{a}$ \\
Victoria 807 & $34,79 \mathrm{a}$ & $8,89 \mathrm{a}$ & $10,68 \mathrm{~cd}$ & $49,89 \mathrm{~b}$ & $39,65 \mathrm{~b}$ & $10,24 \mathrm{a}$ & $31,38 \mathrm{~b}$ & $8,27 \mathrm{a}$ \\
V2000 & $23,39 \mathrm{c}$ & $9,93 \mathrm{a}$ & $16,25 \mathrm{a}$ & $43,59 \mathrm{c}$ & $33,23 \mathrm{c}$ & $10,35 \mathrm{a}$ & $26,01 \mathrm{c}$ & $7,23 \mathrm{a}$ \\
M742 & $29,33 \mathrm{~b}$ & $9,13 \mathrm{a}$ & $12,83 \mathrm{~b}$ & $49,54 \mathrm{~b}$ & $39,29 \mathrm{~b}$ & $10,25 \mathrm{a}$ & $32,23 \mathrm{~b}$ & $7,06 \mathrm{a}$ \\
IAC Uruguai & $37,73 \mathrm{a}$ & $7,33 \mathrm{~b}$ & $9,52 \mathrm{~d}$ & $55,84 \mathrm{a}$ & $44,91 \mathrm{a}$ & $10,94 \mathrm{a}$ & $35,94 \mathrm{a}$ & $8,97 \mathrm{a}$
\end{tabular}

Médias seguidas por letras distintas na coluna diferem entre si (teste $\mathrm{SNK}, \mathrm{P}<0,05$ ).

${ }^{1} \mathrm{CV}=7,73 ;{ }^{2} \mathrm{CV}=7,28 ;{ }^{3} \mathrm{CV}=8,24 ;{ }^{4} \mathrm{CV}=4,58 ;{ }^{5} \mathrm{CV}=5,35 ;{ }^{6} \mathrm{CV}=7,16 ;{ }^{7} \mathrm{CV}=6,08 ;{ }^{8} \mathrm{CV}=14,89$.

${ }^{*}$ Valores em porcentagem da matéria seca.

Em relação aos teores de $\mathrm{PB}$, não foram observadas diferenças $(\mathrm{P}>0,05)$ entre cinco dos seis genótipos estudados, apenas o genótipo IAC Uruguai teve menor teor protéico que os demais
(Tab. 2). Tal resultado pode estar relacionado ao seu maior teor de MS em relação aos demais $(\mathrm{r}=-0,75 ; \mathrm{P}<0,05)$, isso pode indicar que a planta estava em estádio mais avançado de maturação, 
bem como à possibilidade de ocorrência de perdas de aquênios, pois o IAC Uruguai é de ciclo tardio e, portanto, permanece mais tempo exposto ao ataque de pássaros. Valores de PB superiores aos desse experimento foram observados por Almeida et al. (1995), 11,7\%; Valdez et al. (1988), 10,6\% e Henrique et al. (1998), 11,1\% e 13,6. Segundo Van Soest (1994) as plantas têm tendência de acumular estruturas de parede celular com o avançar da idade, o que leva à diluição de compostos do conteúdo celular, com conseqüente redução de seus teores. De acordo com Van Soeste (1994), as exigências de PB para o adequado funcionamento ruminal são obtidas da dieta ou da reciclagem endógena de nitrogênio $(\mathrm{N})$. Em situações de dietas pobres em PB com teor menor que 6-8\%, a reciclagem endógena de $\mathrm{N}$ não é suficiente para suprir as exigências, ficando, assim, prejudicada a digestibilidade ou a ingestão do alimento. Neste estudo, as silagens de todos os genótipos apresentaram níveis de $\mathrm{PB}$ que satisfazem à exigência mínima ruminal.

Os genótipos com sementes produtoras de óleo, V2000 e M742, apresentaram valores de EE maiores $(\mathrm{P}<0,05)$ que os dos genótipos confeiteiros (Tab. 2). Mizubuti et al. (2002) encontraram teor de $8,0 \%$ de EE, menor que os obtidos para as silagens deste experimento, o que pode ser devido à ensilagem em estádio inicial de maturação, pois segundo Castiglioni et al. (1994), o enchimento dos aquênios termina com a maturação fisiológica da planta, fase na qual se definem os teores de EE do girassol. Câmara et al. (1999), ao trabalharem com o cultivar Cargil 11 em quatro diferentes épocas de corte, observaram valores de EE que variaram de 2,4\% a $18,9 \%$ para as épocas de corte um e quatro respectivamente. A variabilidade encontrada nos teores de EE nos diferentes experimentos, parcialmente, pode ser explicada pela grande diversidade existente entre os diferentes genótipos de girassol.

Os menores valores de FDN foram obtidos para os genótipos V2000 e Mycogen 93338, que diferiram $(\mathrm{P}<0,05)$ dos demais (Tab. 2). $\mathrm{O}$ maior valor observado foi para o genótipo IAC Uruguai, que também apresentou diferença em relação aos demais. Houve tendência de os genótipos com maiores teores de matéria seca apresentarem maiores teores de FDN ( $\mathrm{r}=0,77$; $\mathrm{p}<0,05)$. Rezende et al. (2001), ao avaliarem três cultivares de girassol em diferentes idades de maturação, encontraram aumentos nos teores de MS e FDN com o avançar da idade da planta com médias que variaram de $22,9 \%$ a $28,1 \%$ e $34,2 \%$ a $46,0 \%$ para MS e FDN respectivamente. Valores de FDN semelhantes aos das silagens deste experimento foram observados por Stehling (2001), com média de 48,0\% de FDN nas silagens sem inoculantes. Valor de FDN menor, $41,7 \%$, foi verificado por Rodrigues et al. (2001) e valores maiores foram obtidos por Souza (2002) para o cultivar MG4, na quinta época de corte e por Almeida et al. (1995), $52,5 \%$ e $65.9 \%$, respectivamente.

Em relação aos valores de FDA (Tab. 2), houve tendência de maiores teores para os materiais com maiores teores de MS $(\mathrm{r}=0,80 ; \mathrm{P}<0,01)$ e de FDN ( $\mathrm{r}=0,98 ; \mathrm{P}<0,01)$, pois no girassol, os teores de FDA são muito próximos aos de FDN devido aos baixos teores de hemicelulose. A variação entre os valores de FDA (Tab. 2), está de acordo com a variação de 39,2\% a 41,5\% observada por Silva et al. (1998). Mizubuti et al. (2002) verificaram valor de FDA iqual a 46,3\%, maior que os valores obtidos neste experimento. A variação entre os teores de FDA dos materiais pode ser devida à diferença de plantio, ao clima, ao momento de colheita e às características de cada genótipo, como às proporções das diferentes partes da planta (Haste, folha e capítulo).

Não houve diferença significativa $(\mathrm{P}>0,05)$ entre os teores de hemicelulose das silagens estudadas (Tab. 2). Teores de hemicelulose próximos aos das silagens deste experimento foram obtidos por Valdez et al. (1988), 13,5\% e Tomich (2004), $10,1 \%$. Henrique et al. (1998) verificaram menores teores para os cultivares S-503 e C-11, $5,0 \%$ e $5,5 \%$, respectivamente. O mais baixo teor de celulose foi observado para o genótipo V2000 e o mais alto para o IAC Uruguai. Valores intermediários de celulose foram obtidos para os genótipos Victoria 627, Victoria 807 e M742 (Tab. 2). Assim como para os teores de FDN e FDA, foi observada uma tendência de maiores teores de celulose para as silagens com maiores valores de $\mathrm{MS}(\mathrm{r}=0,79 ; \mathrm{P}<0,01)$, o que pode estar relacionado a um estádio mais avançado de maturação, pois as plantas acumulam estruturas de parede celular com o avançar da idade (Van Soest, 1994). Os teores de celulose observados para as silagens deste experimento foram 
semelhantes aos observados por Souza et al. (2005). Não houve diferença $(\mathrm{P}>0,05)$ entre os teores de lignina das silagens dos seis genótipos estudados. Os valores dos conteúdos de lignina obtidos para as silagens são semelhantes aos obtidos por Porto et al. (2006) para os genótipos V200, 7,7\% e Rumbosol 91, 7,9\%. Valores superiores foram obtidos por McGuffey e Schingoethe (1980), média de 11,8\%.

Os valores de digestibilidade in vitro da matéria seca (DIVMS), nitrogênio amoniacal sobre nitrogênio total $\left(\mathrm{N}-\mathrm{NH}_{3} / \mathrm{NT}\right)$ e $\mathrm{pH}$ estão na Tab.3.

Tabela 3. Valores de digestibilidade in vitro da matéria seca (DIVMS), pH e nitrogênio amoniacal/nitrogênio total $\left(\mathrm{N}-\mathrm{NH}_{3} / \mathrm{NT}\right)$ das silagens de genótipos de girassol (Helianthus annuus) confeiteiros e produtores de óleo

\begin{tabular}{lccc}
\hline Genótipos & DIVMS $^{1}(\%)$ & $\mathrm{pH}^{2}$ & $\mathrm{~N}-\mathrm{NH}_{3} / \mathrm{NT}^{3}$ \\
\hline Mycogen 93338 & $54,53 \mathrm{a}$ & $4,07 \mathrm{~b}$ & $7,01 \mathrm{a}$ \\
Victoria 627 & $48,01 \mathrm{~b}$ & $4,55 \mathrm{ab}$ & $8,65 \mathrm{a}$ \\
Victoria 807 & $45,09 \mathrm{bc}$ & $4,76 \mathrm{a}$ & $7,79 \mathrm{a}$ \\
V2000 & $51,97 \mathrm{a}$ & $4,32 \mathrm{ab}$ & $8,06 \mathrm{a}$ \\
M742 & $45,68 \mathrm{bc}$ & $4,58 \mathrm{ab}$ & $10,26 \mathrm{a}$ \\
IAC Uruguai & $43,26 \mathrm{c}$ & $4,80 \mathrm{a}$ & $7,31 \mathrm{a}$ \\
\hline
\end{tabular}

Médias seguidas por letras distintas na coluna diferem entre si (teste $\mathrm{SNK}, \mathrm{P}<0,05$ ).

${ }^{1} \mathrm{CV}=6,07 ;{ }^{2} \mathrm{CV}=6,91 ;{ }^{3} \mathrm{CV}=17,96$.

As diferenças encontradas nos valores de DIVMS para as silagens podem ser explicadas pelos teores de frações fibrosas dos materiais, pois silagens com maiores teores de FDN e FDA apresentaram tendência de menores valores de DIVMS (Tab. 3), o que pode ser confirmado pelas altas correlações entre teores de FDN ( $\mathrm{r}=$ $0,81 ; \mathrm{P}<0,05)$ e FDA $(\mathrm{r}=0,81 ; \mathrm{P}<0,05)$ com os valores de DIVMS. Valores de DIVMS próximos aos deste experimento foram obtidos por Porto et al. (2006) com valores que variaram de $48,9 \%$ a $51,0 \%$ e Souza (2002) com valores que se situaram entre $44,0 \%$ e $59,4 \%$. Segundo McDonald et al. (1991) o declínio na digestibilidade com o avançar da idade é, principalmente, um resultado do aumento do conteúdo de carboidratos estruturais, os quais são menos digestíveis que os componentes solúveis das plantas.

Os valores de $\mathrm{N}-\mathrm{NH}_{3} / \mathrm{NT}$ observados nas silagens, conforme pode ser verificado na Tab. 3, não diferiram entre si $(\mathrm{P}>0,05)$. Valores de $\mathrm{N}$ $\mathrm{NH}_{3} / \mathrm{NT}$ semelhantes foram verificados por Rodrigues et al. (2001), 9,6\% e Pereira (2003), média de 7,5\%, para a abertura de silos aos 56 dias. Noguera (2000) ao trabalhar com silagem de girassol com diferentes proporções de capítulo obteve teores de $\mathrm{N}-\mathrm{NH}_{3} / \mathrm{NT}$, que variaram de
$14,2 \%$ a $17,5 \%$, maiores que os observados neste experimento. Segundo McDonald et al. (1991) altos teores de $\mathrm{N}-\mathrm{NH}_{3} / \mathrm{NT}$ estão altamente correlacionados com a ocorrência de fermentações secundárias, pelo aumento da atividade clostridiana e de enterobactérias, que reduzem o valor nutricional da silagem pelo catabolismo dos aminoácidos.

Em relação ao $\mathrm{pH}$, observou-se tendência de os materiais com maiores teores de MS apresentarem maiores valores de $\mathrm{pH}(\mathrm{r}=0,75$; $\mathrm{P}<0,05)$, (Tab. 2 e Tab. 3).Observação semelhante foi feita por Rezende et al. (2001) que, ao avaliarem três cultivares de girassol, em diferentes idades de maturação, encontraram aumentos nos valores de $\mathrm{pH}$ com o avançar da idade da planta. Segundo Van Soest (1994), silagens com baixos teores de MS deveriam ter valores de $\mathrm{pH}$ inferiores a 4,4, pois silagens com alto $\mathrm{pH}$ e baixa MS indicam fermentação proteolítica e desenvolvimento de aminas e ácido butírico, mas em silagens com altos teores de MS o pH tem uma importância menor. Valores de $\mathrm{pH}$ próximos aos do presente experimento foram encontrados por Valdez et al. (1988), 4,4; Henrique et al. (1998); 4,35 e Tomich (1999) com média geral de 4,67 para as silagens de treze cultivares. 
No emprego dos dados da Tab. 1 para se classificar as silagens, as diferenças entre os genótipos para as diferentes características estudadas não permitiram uma classificação simplificada, e uma mesma silagem recebeu diferentes classificações em razão do parâmetro avaliado. Para os teores de MS, as silagens dos genótipos Mycogen 93338 e V2000 foram classificadas como de média qualidade, já as demais foram classificadas como de muito boa qualidade, o que demonstra a necessidade de se ensilar o girassol com adequados teores de MS para serem atingindos esses valores.

Para os valores de $\mathrm{pH}$, apenas as silagens do genótipo Mycogen 93338 foram classificadas como de boa qualidade, as do Victoria 627, V2000 e M742 foram classificadas como de média qualidade e as dos genótipos Victoria 807 e IAC Uruguai classificadas como de qualidade ruim. Este resultado sugere a necessidade de uma nova classificação específica quanto aos valores de $\mathrm{pH}$, pois valores de $\mathrm{pH}$ de 3,6 a 3,8 propostos para se classificarem as silagens de milho como de muito boa qualidade, são difíceis de serem atingidos pelas silagens de girassol que apresentam adequados teores de MS.

Quanto aos valores de $\mathrm{N}-\mathrm{NH}_{3} / \mathrm{NT}$, apenas a silagem do genótipo M742 apresentou teor de N$\mathrm{NH}_{3} / \mathrm{NT}$ superior ao limite máximo de $10 \%$ para se classificarem as silagens como de muito boa qualidade. Entretanto, como não houve diferença $(\mathrm{P}>0,05)$ entre os valores de $\mathrm{N}-\mathrm{NH}_{3} / \mathrm{NT}$, todas as silagens foram consideradas como de muito boa qualidade para esse parâmetro.

Em relação aos valores de DIVMS, a silagem do genótipo Mycogen 93338 foi classificada como de boa qualidade e as demais como de média qualidade. Essa classificação intermediária, em parte, deu-se pela necessidade de ensilagem em estádios mais avançados de maturação (100\% de grãos maduros) para se atingirem adequados valores de MS nas silagens, já que nesta fase as plantas apresentam maiores concentrações de constituintes de parede celular que são menos digestíveis.

\section{CONCLUSÕES}

As silagens dos genótipos confeiteiros, assim como as silagens dos genótipos produtores de óleo foram classificadas como de boa qualidade para os parâmetros avaliados, o que demonstra o potencial do girassol como uma opção para produção de silagem na época da safrinha.

\section{REFERÊNCIAS BIBLIOGRÁFICAS}

ALMEIDA, M.F.; VON TIESENHOUSEN, I.M.E.; AQUINO, L.H. et al. Composição química e consumo voluntário das silagens de sorgo, em dois estádios de corte, girassol e milho para ruminantes. Cienc. Prat., v.19, p.315-321, 1995.

BENACHIO, S. Niveles de melaza en silo experimental de millo crillo (Sorghum vulgare). Agron. trop., v.14, p.291-297, 1965.

CÂMARA， G.M.S.; SILVA， S.C.; ANDRADE, F.M.E. et al. Determinaçâo do momento ideal de colheita do girassol (Helianthus annus L.) para ensilagem durante a safrinha de 1997. In: REUNIÃO NACIONAL DE PESQUISA DE GIRASSOL, 13., 1999, Itumbiara. Anais... Londrina: Embrapa Soja, 1999, p.123-125. (Documentos, 135).

CASTIGLIONI, V.B.R.; BALLA, A.; CASTRO, C. et al. Fases de desenvolvimento da planta do girassol. Londrina: Embrapa Soja, 1994. 24p. (Documentos, 58).

CASTRO, C.; CASTIGLIONI, V.B.R.; BALLA, A. $A$ cultura do girassol: tecnologia de produção. 2a ed. Londrina: Embrapa Soja, 1997. 20p. (Documentos, 67).

HENRIQUE, W.; ANDRADE, J.B.; SAMPAIO, A.A.M. Silagem de milho, sorgo, girassol e suas consorciações. III. Coeficientes de Digestibilidade. In: SOCIEDADE BRASILEIRA DE ZOOTECNIA, REUNIÃO ANUAL, 35., 1998, Botucatu. Anais... Botucatu: SBZ, 1998. p.382-384.

McDONALD, P.; HENDERSON, A.R.; HERON, S. (Eds). The biochemistry of silage. 2.ed. Marlow: Chalcombe Publications, 1991. 340p.

McGUFFEY, R. K.; SCHINGOETHE, D. J. Feeding value of high oil variety of sunflowers as silage to laetantig dairy cows. J. Dairy Sci., v.63, p.1109-1113, 1980.

MIZUBUTI, I.Y.; RIBEIRO, E.L.A; ROCHA, M. A. et al. Consumo e digestibilidade aparente das silagens de milho (Zea mays L.), sorgo (Sorghum bicolor (L.) Moench) girassol (Helianthus annuus L.). Rev. Soc. Bras. Zootec., v.31, p.267-272, 2002.

NOGUEIRA, F.A.S. Qualidade das silagens de hibridos de sorgo de porte baixo com e sem tanino e de colmo seco e suculento, e seus padrões de fermentação, em condições de laboratório. 1995. 39f. Dissertação (Mestrado) - Escola de Veterinária, Universidade Federal de Minas Gerais, Belo Horizonte. 
NOGUERA, J. R. R. Qualidade de silagens de quatro cultivares de girassol ensilados com diferentes proporções da planta. 2000. 17f. Dissertação (Mestrado) - Escola de Veterinária, Universidade Federal de Minas Gerais, Belo Horizonte.

OFFICIAL methods of analysis. 16 ed. Washington, D.C.: AOAC, 1995, 2000p.

PAIVA, J.A.J. Qualidade da silagem da região metalúrgica de Minas Gerais. 1976, 85f. Dissertação (Mestrado) - Escola de Veterinária, Universidade Federal de Minas Gerais, Belo Horizonte.

PEREIRA, L.G.R. Avaliação do potencial forrageiro da cultura do girassol (Helianthus annuus L.) para produção de silagem. 2003, 88f. Tese (Doutorado) Escola de Veterinária, Universidade Federal de Minas Gerais, Belo Horizonte.

PEREIRA, L.G.R.; GONÇALVES, L.C.; RODRIGUES, J.AS. et al. Avaliação de diferentes épocas de ensilagem da cultura de girassol (Helianthus annuus 1.). II- Produção de matéria natural e matéria seca por hectare e matéria seca da planta, capítulo, folha e haste. In: REUNIÃO NACIONAL DE PESQUISA DE GIRASSOL, 13., 1999, Londrina. Anais... Londrina: EMBRAPA Soja, 1999. p.123-125. (Documentos, 135).

PORTO, P.P.; SALIBA, E.O.S.; GONÇALVES, L.C. et al. Frações da parede celular e digestibilidade in vitro da materia seca de três genótipos de girassol ensilados com aditivos. Arq. Bras. Med. Vet. Zootec., v.58, p.99-107, 2006.

REZENDE, A.V.; EVANGELISTA, A.R.; SIQUEIRA, G. R. et al. Qualidade da silagem de girassol (Helianthus annuus L) 1. Diferentes idades de maturação na safrinha . In: REUNIÃO ANUAL DA SOCIEDADE BRASILEIRA DE ZOOTECNIA, 38., 2001, Piracicaba. Anais... Piracicaba: SBZ, 2001. p.234-235.

RIBEIRO, E.L.A.; ROCHA, M.A.; MIZUBUTI, I.Y. et al. Silagens de girassol (Helianthus annuus L.), milho ( Zea mays L.), sorgo ( Sorghum bicolor (L.) Moench) para ovelhas em confinamento. Cienc. Rural, v.32, p.299-302, 2002.

RODRIGUES, P.H.M.; ANDRADE, S.J.T.; ALMEIDA, T.F. et al. Valor nutritivo de silagens inoculadas com bactérias ácido-lácticas. 3. Inoculação da silagem de girassol. IN: REUNIÃO ANUAL DA SOCIEDADE BRASILEIRA DE ZOOTECNIA, 38., 2001, Piracicaba. Anais... Piracicaba: SBZ, 2001. p.915-916.
SILVA, AW.L.; MACEDO, A.F.; NETO, W.H. et al. Efeito da densidade de semeadura sobre a produtividade e composição bromatológica de silagens de girassol. In: SOCIEDADE BRASILEIRA DE ZOOTECNIA, REUNIÃO ANUAL, 35., 1998, Botucatu. Anais... Botucatu: SBZ, 1998. p.635-637.

SISTEMA de análises estatísticas - SAEG. Versão 7.0. Viçosa: UFV, 1997.

SOUZA, B.P.S. Momento de colheita de quatro genótipos de girassol (Helianthus annuus L.). 2002. 24f. Dissertação (Mestrado) - Escola de Veterinária, Universidade Federal de Minas Gerais, Belo Horizonte.

SOUZA, B.P.S.; COELHO, S.G.; GONÇALVES, L.C. et al. Composição bromatológica da silagem de quatro genótipos de girassol ensilados em cinco diferentes idades de cortes. Arq. Bras. Med. Vet. Zootec., v.57, supl.2, p.204-211, 2005.

STHELING, C.A.V. Avaliação da qualidade das silagens de quatro cultivares de girassol contendo aditivos. 2001. 32f. Dissertação (Mestrado) - Escola de Veterinária, Universidade Federal de Minas Gerais, Belo Horizonte.

TILLEY, J.M.A.; TERRY, R.A. A two-stage technique for the "in vitro" digestion of forage crops. J. Br. Grassl. Soc., v.18, p.104-111, 1963.

TOMICH, T.R. Avaliação das silagens de treze cultivares de girassol (Helianthus annuus L.) participantes do ensaio nacional. 1999. 60f. Dissertação (Mestrado) - Escola de Veterinária, Universidade Federal de Minas Gerais, Belo Horizonte.

TOMICH, T.R.; GONÇALVES L. C; TOMICH R. G. P. et al. Características químicas e digestibilidade in vitro das silagens de girassol. Rev. Bras. Zootec., v.33, supl.1, p.1672-1682, 2004

VALDEZ, F. R.; HARRISON, J. H.; FRASEN, S. C. Effect of feeding sunflower silage on milk production, milk composition and rumen fermentation of lactating cows. J. Dairy Sci., v.71, p.2462-2469, 1988.

VAN SOEST, P.J. (Ed). Nutritional ecology of the ruminant. 2.ed. Ithaca: Cornell University, 1994. 476p.

VAN SOEST, P.J., ROBERTSON, J.B., LEWIS, B.A. Methods for dietary fiber, neutral detergent, and nonstarch polysaccharides in relation to animal nutrition. J. Dairy Sci.. v.74, p.3583-3597, 1991. 